\title{
Editorial
}

\section{Metabolism of Photosynthetic Organisms}

\author{
Tatyana Savchenko ${ }^{1, *(1)}$ and Andrej Frolov ${ }^{2,3, *}$ \\ 1 Institute of Basic Biological Problems, Pushchino Scientific Center for Biological Research, \\ Russian Academy of Sciences, 142290 Pushchino, Russia \\ 2 Department of Bioorganic Chemistry, Leibniz-Institute of Plant Biochemistry, Weinberg 3, \\ 06120 Halle (Saale), Germany \\ 3 Department of Biochemistry, St. Petersburg State University, 199034 St. Petersburg, Russia \\ * Correspondence: savchenko_t@rambler.ru (T.S.); Andrej.Frolov@ipb-halle.de (A.F.)
}

Citation: Savchenko, T.; Frolov, A. Metabolism of Photosynthetic

Organisms. Life 2021, 11, 946.

https: / / doi.org/10.3390/

life11090946

Received: 6 September 2021

Accepted: 7 September 2021

Published: 10 September 2021

Publisher's Note: MDPI stays neutral with regard to jurisdictional claims in published maps and institutional affiliations.
According to multiple definitions of life, metabolism is an indispensable characteristic of living organisms. When it comes to autotrophic organisms executing the biosynthesis of organic molecules from the simple inorganic materials, such as water, carbon dioxide, and mineral salts, their metabolism, in essence, implements the transformation of the nonliving matter into components of a life form. Photoautotrophic carbon fixation occurring in green plants and photosynthetic bacteria can be considered as the main interface between non-living matter and living organisms, while the complex system of biochemical reactions of central and specialized metabolism enables organisms to maintain growth, development, reproduction, and interaction with the environment.

In this Special Issue of Life, we present a collection of articles dedicated to various aspects of research of metabolism in photosynthetic organisms.

Chaudhary and Kalkal [1] present the results of bioinformatics analysis of publicly available transcriptome data generated from the root and shoot tissues of rice genotypes grown under optimal and nitrogen starvation conditions revealing the differentially expressed and alternatively spliced genes. This work extends our understating of nitrogen utilization efficiency mechanisms in the important crop plant.

The occurrence of residual pharmaceuticals in the environment attracted significant attention from the scientific community during the last few decades. In the work of Kudrna et al. [2], lettuce (Lactuca sativa L.) plants were employed to probe the effects of one of the most widely used drugs, acetaminophen, on their physiological characteristics. The obtained data demonstrate the high sensitivity of plants to chronic exposure to this omnipresent contaminant.

The manuscript by Mihalik et al. [3] describes the substantial research on isolation and characterization of the specific gene for the production of acetylated triacylglycerols in Euonymus plants. Transgenic host plants overexpressing the diacylglycerol acetyltransferase gene from E. europaeus produced and accumulated acetylated triacylglycerols in maturating seeds. Thereby, the difference in fatty acid composition of acetylated triacylglycerols was demonstrated. The presented data provide generalized guidance for the application of the genes from Euonymus plants in biofuel production.

The work by Glabonjat et al. [4] is an important extension of the growing body of knowledge on the biochemistry of arsenosugars and arsenolipids with a special emphasis on their potentially deleterious effects on the organisms representing the basic food web components. The authors present evidence for a trophic transfer of organoarsenicals from the phytoplankton to the zooplankton community and demonstrate the efficient bacterial mineralization of lysis-released organoarsenicals back to inorganic oxyanions before they sink to the sediments. The paper will be of interest to scientists studying the biogeochemical cycling of arsenic.

Comprehensive reviews presented in our Special Issue summarize the recent research advances on the carbon metabolism of purple non-sulfur bacteria, oxidative stress- 
specific alteration of pant metabolism, and the role of microRNAs in the regulation of plant metabolism and stress tolerance [5-7].

Petushkova et al. [5] present a very detailed and comprehensive review summarizing the recent data on the presence and diversity of anaplerotic pathways in purple non-sulfur bacteria. Purple non-sulfur bacteria produce a broad selection of valuable compounds, including molecular hydrogen. These organisms can be cultivated in organic wastewaters, such as fermentation wastes. Thus, these bacteria can be extensively used in biotech applications.

Savchenko and Tikhonov [6] summarize the available data on the alterations in central metabolism associated with plant adaptation to oxidative stress. The analysis provides a theoretical basis for the generation of plants with improved tolerance to oxidative stress and the development of metabolic markers applicable in research and agricultural practice.

The group of authors (Chaudhary et al.) [7] has reviewed the role of microRNAs in plant stress response and their potential use as targets for developing stress-tolerant crops. MicroRNAs mediate post-transcriptional gene silencing and fine-tuning of the regulation of many abiotic and biotic stress-responsive genes in plants. Thus, these molecules might be considered novel targets for engineering stress-tolerant crop varieties.

We believe that the original research and review articles collected in this Special Issue will be interesting to a broad audience of scientists studying physiological, biotechnological, and ecological aspects of autotrophic metabolism.

Author Contributions: T.S. and A.F. wrote the manuscript. Both authors have read and agreed to the published version of the manuscript.

Funding: This work is supported by the Ministry of Science and Higher Education of the Russian Federation in accordance with agreement № 075-15-2020-922 date 16 November 2020 on providing a grant in the form of subsidies from the Federal budget of Russian Federation. The grant was provided for state support for the creation and development of a World-class Scientific Center "Agrotechnologies for the Future."

Acknowledgments: Tatyana Savchenko and Andrej Frolov thank all the contributors of the Special Issue of Life (ISSN 2075-1729): The Metabolism of Photosynthetic Organisms. The guest editors also wish to recognize the valuable contribution of all those involved in the peer-review process.

Conflicts of Interest: The authors declare no conflict of interest.

\section{References}

1. Chaudhary, S.; Kalkal, M. Rice Transcriptome Analysis Reveals Nitrogen Starvation Modulates Differential Alternative Splicing and Transcript Usage in Various Metabolism-Related Genes. Life 2021, 11, 285. [CrossRef] [PubMed]

2. Kudrna, J.; Hnilicka, F.; Kubes, J.; Vachova, P.; Hnilickova, H.; Kuklova, M. Effect of Acetaminophen (APAP) on Physiological Indicators in Lactuca sativa. Life 2020, 10, 303. [CrossRef] [PubMed]

3. Mihálik, D.; Lančaričová, A.; Mrkvová, M.; Kaňuková, Š.; Moravčíková, J.; Glasa, M.; Šubr, Z.; Predajňa, L.; Hančinský, R.; Grešíková, S.; et al. Diacylglycerol Acetyltransferase Gene Isolated from Euonymus europaeus L. Altered Lipid Metabolism in Transgenic Plant towards the Production of Acetylated Triacylglycerols. Life 2020, 10, 205. [CrossRef] [PubMed]

4. Glabonjat, R.A.; Blum, J.S.; Miller, L.G.; Webb, S.M.; Stolz, J.F.; Francesconi, K.A.; Oremland, R.S. Arsenolipids in Cultured Picocystis Strain ML and Their Occurrence in Biota and Sediment from Mono Lake, California. Life 2020, 10, 93. [CrossRef] [PubMed]

5. Petushkova, E.; Mayorova, E.; Tsygankov, A. TCA Cycle Replenishing Pathways in Photosynthetic Purple Non-Sulfur Bacteria Growing with Acetate. Life 2021, 11, 711. [CrossRef] [PubMed]

6. Savchenko, T.; Tikhonov, K. Oxidative Stress-Induced Alteration of Plant Central Metabolism. Life 2021, 11, 304. [CrossRef] [PubMed]

7. Chaudhary, S.; Grover, A.; Sharma, P.C. MicroRNAs: Potential Targets for Developing Stress-Tolerant Crops. Life 2021, 11, 289. [CrossRef] [PubMed] 